\title{
Sustainable economic development in the European Union and COVID-19
}

\author{
Chara Vavoura ${ }^{1} \cdot$ loannis Vavouras ${ }^{2}$ (D)
}

Received: 9 April 2021 / Accepted: 26 June 2021 / Published online: 26 July 2021

(c) Japan Association for Evolutionary Economics 2021

\begin{abstract}
The paper has two basic objectives. The first, is to present the evolution of the process of sustainable development in the European Union (EU). We provide evidence that over time, the concept of sustainable development as a broad policy objective has been steadily declining in importance giving way to the less multidimensional strategy of green growth. We argue that the green growth strategy is actually based on the strategic selection of the traditional economic growth model, taking into account certain environmental aspects. We show that environmental protection expenditure is growing much slower than per capita income. Looking at the investment on environmental protection, we document a clear falling trend. Our findings imply that both the social and the environmental dimension of sustainability have been losing ground and the traditional goal of economic growth is being restored. The second, is to provide some assessment of the impact of the coronavirus pandemic on the process of sustainable development in the EU. Considering the relevant EU forecasts on the immediate effects of the pandemic, we conclude that it will severely hinder the process of sustainability in the EU in the short term. The long-term effects of the pandemic cannot even be outlined, especially at the level of the individual member states. Nevertheless, the effectiveness of the Recovery and Resilience Facility as key instrument of recovery and of national recovery and resilience plans, will play a decisive role in minimising or even neutralising the negative longer-term effects of the coronavirus pandemic.
\end{abstract}

Keywords Economic development · Sustainable development · Green growth · Environmental protection · COVID-19 · European Union

\footnotetext{
We thank Professor Theodore Mariolis, Guest Editor of Evolutionary and Institutional Economics Review and two anonymous referees for their comments and suggestions.

Ioannis Vavouras

vavouras@panteion.gr

1 Department of Economics of the University of Athens, Athens, Greece

2 Panteion University of Social and Political Sciences, Sygrou 136, 17671 Athens, Greece
} 
JEL Classification Q01 · Q56·Q57

\section{Introduction}

This paper constitutes a first major attempt to evaluate the impact of the COVID-19 pandemic on the sustainable development goals of the European Union (EU). To address this issue, we look into the evolution of sustainable development during the pre-COVID era both as a theoretical objective and as an empirically verified policy plan.

Sustainable development has been at the center of the economic research of the last four decades and the core strategy of international organisations, including the EU. The term refers to three basic components. Namely the economic component, which is associated with balanced growth, the environmental component that refers to the preservation of the ecosystem, and the social component, guarantying inter- and intra-generational equality. We show that, against the common feeling of increasing ecological conscience and concern, the importance of sustainability has been gradually weakening in the EU over the last 15 years. In particular, on the theoretical level, we argue that, following the example set by the United Nations (UN), the EU has gradually moved away from the aforementioned three-pillar actually intended content of sustainable development towards the pursuit of green growth, an aim limited to only two components, the economic and the environmental. The green growth strategy followed at global and European level is now very clear that it is based on the strategic choice of a model of economic growth that takes into account only specific environmental aspects.

On the applied level, we find little support of even this two-dimensional aim. In the EU, environmental protection expenditure has not yet come close to catching up with economic growth and the investment in environmental protection has in fact been declining since 2010. Testing the Environmental Kuznets Curve (EKC) hypothesis that there is an inverted-U relationship between economic growth and environmental degradation, we fail to establish empirical support using the EU data for the period between 2006 and 2019. Consequently, our paper contributes to the literature by showing that, in the EU, the pre-COVID era has been characterised by a gradual restoration of the traditional yet unsustainable economic growth.

Regarding the post-pandemic times, we investigate the impact of COVID on the EU sustainable development goals. We argue that, in the short-run we are most likely looking at a sustainability slowdown. In the long-run, the effect appears nuanced and country-dependent. In particular, when it comes to shaping the future of sustainable development, we highlight the importance of the Recovery and Resilience Facility (RRF), which has been established within the Union to support countries and economic sectors hit hardest by the pandemic, by providing loans and grants for the first years of the recovery.

The structure of our paper is as follows. In Sect. 2, we start off by analysing the evolution of sustainable development in the context of international organisations, and in particular the UN and the EU. In Sect. 3, we go on to present the relationship between economic growth and environmental protection in the EU using all 
available Eurostat data which cover the years 2006-2019. In Sect. 4, we attempt to predict the effect of the pandemic on European sustainability and the mechanism through which it could materialise. Finally, in Sect. 5, we discuss our findings and policy implications and conclude.

\section{The evolution of sustainable development}

The issue of sustainable development first becomes a policy pillar by an international organisation or program in $1980^{1}$ and gets recognised as a global objective in 1987 by the UN's World Commission on Environment and Development in its "Brundtland Report" that has since exerted great influence on the adoption of the objective of sustainable development and the shaping of its content. Few years later, the United Nations Conference on Environment and Development (UNCED), taking place in Rio de Janeiro in 1992, adopts the "Rio Declaration on Environment and Development", which defines sustainable development as the development that "meets the needs of the present generation without compromising the ability of future generations to meet their own needs" (World Commission on Environment and Development 1987) and promotes sustainable development as a global ideal of sustained social well-being and a basic concept embodying three fundamental dimensions or components: a social, an economic and an environmental. ${ }^{2}$ A decade later, in the 2002 Johannesburg Summit ("World Summit on Sustainable Development") the content of each of these components is specified. The economic component focuses mainly on ensuring constant economic growth, in turn regarded as a necessary condition for the continuous improvement of social well-being. The environmental component concerns primarily the respect for the limits of the ecosystem to maintain its stable productive base, ensure the protection and quality of natural resources so that they are not over-exploited or their quality is diminished, and safeguard biodiversity. The social component chiefly focuses on ensuring interand intra-generational equality, social integration and cohesion, civic participation, social mobility and respect for cultural diversities (UN 2002). Regarding the way that the three components are interrelated, the UN Commission on Sustainable Development recognises the economic dimension of development as the means for serving its social dimension, which is the aim of sustainable development, whereas the environmental dimension of development is the basis of sustainable development (UN 2001).

Another milestone of sustainable development is the UN Conference on Sustainable Development ("Rio+20") in 2012, which paves the way to the 2030

\footnotetext{
1 Namely the International Union for the Conservation of Nature in its World Conservation Strategy, the World Wildlife Fund and the United Nations Environmental Programme (Pearce et al 1990) in an effort to combine economic development with the preservation of the environment.

2 Its Action Plan "Agenda 21" contained guidelines for setting-up decision-making structures aimed at the sustainability in the belief that an integrated system of environmental and economic accounting would constitute a first step in the direction of incorporating sustainability into the management of the economy (Vavouras 2011).
} 
Agenda. The 2030 Agenda is adopted on September 25th, 2015 at a special UN Summit that defines a set of 17 sustainable development goals (SDGs), 169 targets and $230+$ indicators. ${ }^{3}$ The 17 SDGs are presented in Table 1. The "2030 Agenda" becomes the new global sustainable development agenda (Eurostat 2020a) and it is widely accepted that the 17 SDGs integrate, in a balanced manner, all 3 dimensions of sustainable development: economic, social and environmental. ${ }^{4}$

It must be noted that the definition of sustainable development adopted in 1992 and still accepted today is not a rigorous one and, as a result, the measurement of sustainable development constitutes an extremely difficult undertaking. ${ }^{5}$ However, the acknowledgement of the multidimensional nature of sustainability has, despite all its imperfections, raised issues of the morality of development, and the related economic policies, that the traditional theory of economic growth largely ignores. More specifically, the idea that the unlimited increase of the overall output of the economy could disrupt the balance in the relations between man and the environment has slowly gained ground and, for this reason, the respective economic policy models have been reformed, mainly by incorporating the environmental dimension.

Gradually, however, the goal of sustainable development as a substantive pursuit and not as a mere declaration has given way to that of green growth. At the level of international organisations, the green growth approach is first adopted by the United Nations Economic and Social Council ${ }^{6}$ in 2005 (UNESCAP 2005) which takes the stance that only through economic growth could poverty be eradicated in the long run. The central argument for abandoning sustainable development in favour of green growth is that sustainable development so far remains a general concept without specific substance. This shift results in the reestablishment of economic growth gets as the main objective, but in a way that is respectful to the environment, meaning that it should be accomplished without exerting undue pressure on environmental capabilities (UNESCAP 2005). As a result, it becomes urgent to explore models of environmentally sustainable economic growth, which is referred to as green growth (UNESCAP 2005).

Four years later, in June 2009, the Ministerial Council Meeting of the OECD's member states ${ }^{7}$ sign the "Declaration on Green Growth" proclaiming that the concepts of green and growth are not mutually conflicting but, on the contrary, can be

\footnotetext{
3 "Transforming our World: The 2030 Agenda for Sustainable Development" Resolution is adopted by the General Assembly on 25 September 2015, United Nations, A/RES/70/1, 21 October 2015. For the published version see United Nations (UN 2015).

${ }^{4}$ See the Preamble of the "2030 Agenda".

${ }^{5}$ This occurs mainly because the various individual indicators cannot be aggregated to give us one sole sustainability index based on a single criterion or even just a few. The problem is complicated by the fact that the partial indicators do not have the same socio-economic significance for all countries, so that questions arise of weighting them. Even Agenda 21 is regarded as constituting a political text, rather than a technical guideline (Purvis and Grainger 2004).

${ }^{6}$ It was adopted by the 5th Ministerial Conference on Environment and Development in Asia and the Pacific of the Economic and Social Commission for Asia and the Pacific of the United Nations Economic and Social Council, held in Seoul in March 2005 (UNESCAP 2005).

${ }^{7}$ In which representatives of some other countries took part, namely of Chile, Estonia, Israel, Slovenia and the European Union.
} 
compatible. In this Declaration, it is clearly stated that green investments and the sustainable management of natural resources will be encouraged (OECD 2009a) recognising that investments in the environment constitute a new source of economic growth (OECD 2009b). The OECD sets out to develop a "Green Growth Strategy" (OECD 2009a) that will quantify the potential effects of green growth and estimate the cost of implementing the transition to a sustainable economy. Then, as a way out of the global economic crisis of 2007-2008, the issue of green growth is adopted by the OECD member states in the belief that the effort to recover from the crisis demands an economic development strategy different from what these countries have pursued in the past.

From the analysis presented above, it is evident that green growth is based on the strategic selection of an economic growth model, taking into account certain environmental issues or aspects. It is a concept invented to overcome the trade-offs between economic growth and environmental conservation (Mori and Ueta 2007). It can thus be argued that green growth has moved away from the one-dimensional concept of economic growth, since in addition to the economic dimension, it incorporates the environmental one as well. At the same time, however, it largely neglects the social dimension that constitutes the third and core component of sustainable development. Reconciling this with the declaration of the UN Commission on Sustainable Development stated above, it is evident that in the effort to reconcile the means of sustainable development with its basis, the aim of sustainability has been neglected. We must note that, in the context of green growth, the view that some social goals are served indirectly, has been expressed. In particular regarding the goal of combating poverty, it has been repeatedly argued that the increase of real per capita GDP helps curb "absolute" poverty. ${ }^{8}$ However, the fact that the high economic growth rates achieved by various developing countries in the past have not led to the elimination of poverty proves that this argument cannot be taken for granted.

Moving on to the EU, we observe that its policy closely follows that of the UN and, as expected, sustainable development is a key European goal, which has been incorporated in the European Treaties since $1997 .{ }^{9}$ Nevertheless, within the EU, sustainable development becomes a matter of particular interest only in 2001, when its first "EU Sustainable Development Strategy (EUSDS)" is adopted. ${ }^{10}$ By 2006, this first EUSDS gets renewed ("Renewed EUSDS"11), after reiterating the definition of

\footnotetext{
${ }^{8}$ Poverty can be distinguished into "absolute" and "relative". The first describes the condition where the household income is below a required level to maintain the basic needs of life or the basic means of subsistence. The second describes the condition where the household income is a certain percentage below the median income. In this case "poor" are considered those who lack a socially acceptable level of income or resources compared to the other members of society. For the distinction of these terms, see mainly Foster (1998).

${ }^{9}$ For its current statement in the Treaty, see Consolidated Version of the Treaty on European Union, articles 3(5) and 21(2), Official Journal of the European Union, C 326/26.10.2012.

${ }^{10}$ Commission of the European Communities, Communication from the Commission, A Sustainable Europe for a Better World: A European Union Strategy for Sustainable Development, COM(2001) 264 final, Brussels, 15.5.2001.

${ }^{11}$ Council of the European Union, Renewed EU Sustainable Development Strategy, 10,917/06, Brussels, 26/6/2006.
} 
Table 1 The 17 sustainable development goals of the "2030 Agenda"

$\begin{array}{ll}\text { SDG 1: No poverty } & \text { SDG 10: Reduced inequalities } \\ \text { SDG 2: Zero hunger } & \text { SDG 11: Sustainable cities and communities } \\ \text { SDG 3: Good health and well-being } & \text { SDG 12: Responsible consumption and production } \\ \text { SDG 4: Quality education } & \text { SDG 13: Climate action } \\ \text { SDG 5: Gender equality } & \text { SDG 14: Life below water } \\ \text { SDG 6: Clean water and sanitation } & \text { SDG 15: Life on land } \\ \text { SDG 7: Affordable and clean energy } & \text { SDG 16: Peace, justice and strong institutions } \\ \text { SDG 8: Decent work and economic growth } & \text { SDG 17: Partnership for goals } \\ \text { SDG 9: Industry, innovation and infrastructure } & \end{array}$

Source: United Nations (UN 2015)

sustainable development adopted by the Brundtland Report, to emphasise that sustainable development refers to ensuring the earth's capacity to support all forms of life and is based on the principles of democracy, gender equality, solidarity, the rule of law and respect for human rights. The overall aim of the EUSDS has been to identify and develop actions that will enable the EU to achieve a continuous longterm improvement of the quality of life and living conditions for the benefit of both present and future generations. To achieve this, the EU is committed to promoting a dynamic economy that will ensure prosperity, environmental protection and social cohesion with full employment among its key objectives. ${ }^{12}$

The EUSDS has been reviewed in several occasions to define more clearly its objectives and set new milestones. The most recent milestone set has been the adoption of the UN "2030 Agenda for Sustainable Development" in November 2016, when EU presents its response to the "2030 Agenda" and adopts the UN sustainable development package. ${ }^{13}$ Moreover, to further comply with the "2030 Agenda" and to adopt a new growth strategy aiming to "transform the EU into a fair and prosperous society, with a modern, resource efficient and competitive economy", the European Commission presents the "European Green Deal (EGD)" in December 2019. ${ }^{14}$ The EGD is a set of targets, objectives and intentions planned to be implemented over a period of 10 years. The EGD is the basic part of the new EU growth strategy aiming to make the EU by the year 2050 the first climate-neutral region. However, the analysis of the EGD and in particular of the eight key areas that make it up ${ }^{15}$

\footnotetext{
12 Council of the European Union, Renewed EU Sustainable Development Strategy, 10,917/06, Brussels, 26/6/2006, Annex, page 2, paragraph 1.

13 European Commission, Communication from the Commission to the European Parliament, the European Council, the Council, the European Economic and Social Committee and the Committee of the Regions, "Next Steps for a Sustainable European Future: A European Action for Sustainability", Brussels, 22.11.2016, COM (2016) 739 final.

14 European Commission, Communication from the Commission to the European Parliament, the European Council, the Council, the European Economic and Social Committee and the Committee of the Regions, "the European Green Deal", Brussels, 11.12.2019, COM (2019) 640 final.

15 That is: (1) Increasing the EU's climate ambition for 2030 and 2050. (2) Supplying clean, affordable, secure energy. (3) Mobilising industry for a clean and circular economy. (4) Building and renovating in an energy and resource efficient way. (5) A zero-pollution ambition for a toxic-free environment. (6)
} 
clearly shows that at the EU level, too, the strategic focus is shifting gradually from sustainable development to green growth.

The measurement of the progress towards the achievement of the basic goals and challenges of sustainable development, that is the SDGs, at the EU level is done by the continuous monitoring of the objectives and targets set out in the EUSDS. For this purpose, Eurostat prepares monitoring reports. ${ }^{16}$ The most recent such reportat the time this paper was prepared/written-and the fourth in line is the 2020 Monitoring Report (Eurostat 2020a). It should be noted at this point, that the general progress in terms of sustainability is assessed on the basis of the average annual growth rate over the last 5 years of the scores of the relevant indicators by which the degree of achievement of SDGs is measured. According to this sustainability assessment methodology, over the period 2015-2020, significant progress has been made in almost all SDGs in the EU (Eurostat 2020a), although the discrepancies of the member states towards the SDGs are very large. ${ }^{17}$ Surprisingly, however, the goals dealing with environmental sustainability indicate slow or no progress at the EU level over the same period. ${ }^{18}$

Finally, we must not fail to mention that that the 2020 monitoring report describes the situation in the EU and its member states up to the year 2019 at most and, as a consequence, it does not include the implications of the coronavirus pandemic (Eurostat 2020a). Furthermore, before we proceed, we must make it clear that, in spite of the progress made, no European country and consequently neither the EU as a whole has achieved the SDGs at the onset of the coronavirus pandemic. ${ }^{19}$

\section{The relationship between economic growth and environmental protection in the context of the European Union}

There is an overwhelming literature documenting the relationship between economic growth and environmental quality and, in most cases, the environmental impact of economic growth. A common finding of the relevant studies is that the quality of the environment deteriorates in the early stages of economic growth and then improves

\footnotetext{
Footnote 15 (continued)

Preserving and restoring ecosystems and biodiversity. (7) From "Farm to Fork": a fair, healthy and environmentally friendly food system. (8) Accelerating the shift to sustainable and smart mobility. See, European Commission, "the European Green Deal", Figure 1, p. 3, and also Fetting C (2020), p. 5.

16 We must note that two auxiliary bodies are used for the advancement of sustainable development: The Sustainable Development Observatory (SDO) to promote at the EU level the idea of sustainable development and the European Sustainable Development Network (ESDN) which is an informal network of public administrators and other experts dealing with sustainable development.

17 Ranking from 81.1 SDG indicator score for Finland, to 55.8 SDG Indicator score for Bulgaria (SDSN and IEEP 2020).

18 See Eurostat (2020a), "Synopsis on how has the EU progressed towards the SDGs", p. 12.

19 According to the SDG Indicator for Europe, an indicator that tries to measure the overall success on all the 17 SDGs, the total score for Europe in 2020 was 70.7 (SDSN and IEEP 2020). The discrepancy between 70.7 and 100 depicts in percentage terms the distance that needs to be covered to achieve the SDGs targets.
} 
as the economy grows. That is, initially, environmental pressures increase faster than real GDP and then increase at a slower pace than real GDP (Dinda 2004). This relationship between income level and environmental quality is known as the Environmental Kuznets Curve (EKC). According to the EKC hypothesis, the relationship between economic growth, measured by per capita income, and environmental degradation is of the inverted- $U$ shape.

The explanation for this relationship is that in the early stages of development, and in particular of industrial development, governments and societies prioritize increased production and employment over environmental protection. That is, emphasis is placed on unrestricted economic growth in the light of the strategy "first expansion of production and later cleansing" ("grow first, clean up later"). ${ }^{20}$ When the economy has grown, it becomes possible to be aware of environmental issues, so the emphasis is now placed on environmental protection. ${ }^{21}$ Under these circumstances, economic growth can be considered as a cause of environmental degradation on one hand and a condition of environmental protection on the other. In this part of the paper, we exhaust the data available by Eurostat, which are yearly data for the years 2006-2019 to test the EKC hypothesis in the case of the EU. Given our small dataset, we should interpret our results as indications of general trends rather than focus on the specific numerical results of our empirical analysis.

We start our analysis with the most important indicator of the extent of environmental protection in the EU, which is the national expenditure on environmental protection (NEEP). NEEP measures the resources used by the resident units of a country (households, corporations and government) for protecting the natural environment in a given period. It is calculated as the sum of the running costs of environmental protection activities and investments in environmental protection, including net transfers to the rest of the world (Eurostat 2020b).

It is rather disheartening to observe that NEEP, in the member states of the 27-nation European Union (EU-27), covers a very small percentage of their GDP. To be precise, NEEP in the overall or total economy (households, corporations and government) during the period 2006-2019 averages approximately $2 \%$ of the GDP of the EU member states. Of course, there are some noticeable differences between the EU states. For example, in Belgium and Austria they exceeded the 3\% of GDP, while in Luxembourg they did not exceed the $1 \%$ of GDP. In Greece, NEEP in the total economy was below $1.5 \%$ of GDP, well below the EU-27 average. However, despite cross-country differences, NEEP fails to attract the necessary funding.

Digging deeper, NEEP in the total economy is divided into three parts corresponding to the respective institutional sectors. First, on the expenditure of the corporation's sector that includes both specialised environmental protection producers and ancillary producers who do not sell environmental protection services on the market but undertake environmental protection activities in-house and for their own use, to reduce the negative environmental effects of their main production activity.

\footnotetext{
${ }^{20}$ For an analysis of this strategy, see in particular Pegels and Altenburg (2020) and O' Connor (1996).

21 For a review of the theoretical and empirical research referring to the EKC, mainly in Dinda (2004) and Dietz and Adger (2003).
} 
Second, on the expenditure on environmental protection of general government and non-profit institutions serving households. Third, on the expenditure on environmental protection of households (Eurostat 2020b).

Figure 1 depicts the evolution of the national expenditure on environmental protection, both in total and by institutional sector throughout the EU-27 as a percentage (\%) of GDP during the period 2006-2019. As shown in Fig. 1, corporations' expenditure on environmental protection covers more than $1 \%$ of GDP. That is, it covers each year more than $50 \%$ of the corresponding total NEEP. In 2019, for example, it covered $57.2 \%$ of the total NEEP ( $€$ 154,042.6 million in the total of $€$ $269,108.8$ million). The participation of the public sector and households in NEEP is limited. In 2019, for example, it covered respectively $22.2 \%$ and $20.5 \%$ of the total NEEP ( $€ 59,866.1$ million and $€ 55,200.1$ million, respectively). As a result, national expenditure on environmental protection in the EU is primarily funded by corporations, a phenomenon which is partly attributed to environmental subsidies and similar transfers.

Moving on to investigate the issue of investment in environmental protection in the EU-27 which is of particular importance given that, as we have already stated, investment in the environment is commonly viewed as a new crucial source of economic growth (OECD 2009b). As shown in Fig. 2, environmental protection investments in the whole economy in the EU-27, apart from the fact that they are very limited and do not exceed $0.5 \%$ of GDP, follow a downward trend during the period 2006-2019 both in absolute terms (in millions of euros), as shown by the dashed trend line, as well as expressed as a percentage of GDP (continuous line). They receive their highest absolute amount in 2008 ( $€$ 61,272.6 million), while their lowest in 2016 ( $€ 48,656.0$ million). It is interesting to point out that investments in environmental protection on the part of companies are very low. In 2019, they covered only $1.7 \%$ of their total investments (Eurostat 2020b). This is suggestive of the limited corporate sustainability initiatives and a strong indication that, besides sustainable development, green growth too remains largely a political ideology or rather a political speculation, which has not yet evolved into a strictly defined concept and methodology suitable for formulating and evaluating policies, both at the firm and the national level.

A very interesting task would be to estimate the EKC for the EU as a whole and its individual member states. However, this is a rather impossible task for two main reasons: firstly, because the quality of the environment is not measured by a single indicator but by a set of numerous indicators ${ }^{22}$ that cannot be aggregated in some way to provide an overall one-dimensional index of environmental quality to correlate it with GDP growth. Secondly, the estimated indicators by the Eurostat cover in most cases the period 2006-2019, ${ }^{23}$ which is absolutely limited to conduct any form of statistical analysis. We are therefore limited to the investigation of the relationship

\footnotetext{
${ }^{22}$ For a brief overview of the large number of indicators provided mainly by Eurostat and the European Environmental Agency (EEA) and used to assess the environmental quality at European level, see European Commission (2020a).

${ }^{23}$ See Eurostat Database: Environment.
} 
between the annual growth rate of national expenditure on environmental protection across the EU-27 over the period 2006-2019 for which data are available and compare it with the corresponding GDP growth rate. What we test in fact is a "broad" EKC since the EKC correlates GDP growth with environmental degradation. Nevertheless, given that environmental protection expenditures are directly related to the reduction of environmental degradation, we argue that the correlation between environmental protection spending and GDP growth constitutes a "quasi-EKC".

As shown in Fig. 3, where we depict the evolution of national expenditure on environmental protection (NEEP) for the whole economy and of GDP during the period 2006-2019 measured in logarithmic form (ln), the annual GDP growth rate was higher than the corresponding growth rate of NEEP in the total economy during the period 2006-2019. Overall, environmental protection expenditure in the total economy in the EU-27 during the period 2006-2019 increased from $€ 201,477.6$ million to $€ 269,108.8$ million, corresponding to an overall increase of $33.6 \%$ (average annual growth rate $2.25 \%$ ). During the same period, EU-27 total GDP at market prices increased from $€ 10,113,606.0$ million to $€ 13,963,560.9$ million, corresponding to an overall increase of $38.1 \%$ (average annual growth rate $2.5 \%$ ). ${ }^{24}$ Consequently, given that economic growth occurs at a rate higher than the rate at which environmental degradation is slowing down, we conclude that the EKC hypothesis does not appear to be verified in the case of the EU.

The relationship between NEEP and GDP is best illustrated in Fig. 4 where the annual rates of change of these variables are presented. We observe that the relationship between $(\triangle \mathrm{NEEP} / \mathrm{NEEP})$ and $(\triangle \mathrm{GDP} / \mathrm{GDP})$ is best approximated by a linear function and that the rate of change of NNEP is a little more than half of that of GDP. To get a better understanding of nations' willingness to pay for environmental protection we calculate the income elasticity of environmental expenditure, given by the ratio $(\Delta \mathrm{NEEP} / \mathrm{NEEP}) /(\Delta \mathrm{GDP} / \mathrm{GDP})$. We find that it varies widely from 1 year to the next and the average is 0.9115 , implying that environmental protection is on average a normal good (elasticity is below 1) which leads us to believe that demand for environmental protection increases (or decreases) on average marginally less than proportionally with respect to income. However, there are years (in our dataset these are the years 2008, 2012 and 2019) when elasticity is above one, meaning that on these years environmental protection behaves as a luxury good. Summing up, environmental policy is, on average, expected to follow closely the general economic policy, since both environmental expenditure and total expenditure are expected to grow at similar rates.

These findings are in agreement with the relevant literature reporting income elasticity that is close to 1 , and indicate that, in comparison with past works like for example Pearce and Palmer (2001) who calculate an elasticity just above 1, it

\footnotetext{
${ }^{24}$ This can be discovered and from the comparison of the evolution during the period 2006-2019 of the values of the respective indicators for the EU-27. Taking as a basis the year $2006(2006=100)$, we have that in 2019, the value of the NEEP indicator was 133.6, while the value of the GDP indicator at market prices was 137.7 , and the value of the indicator of investments for environmental protection in total economy was 86.8. Eurostat (2020c).
} 


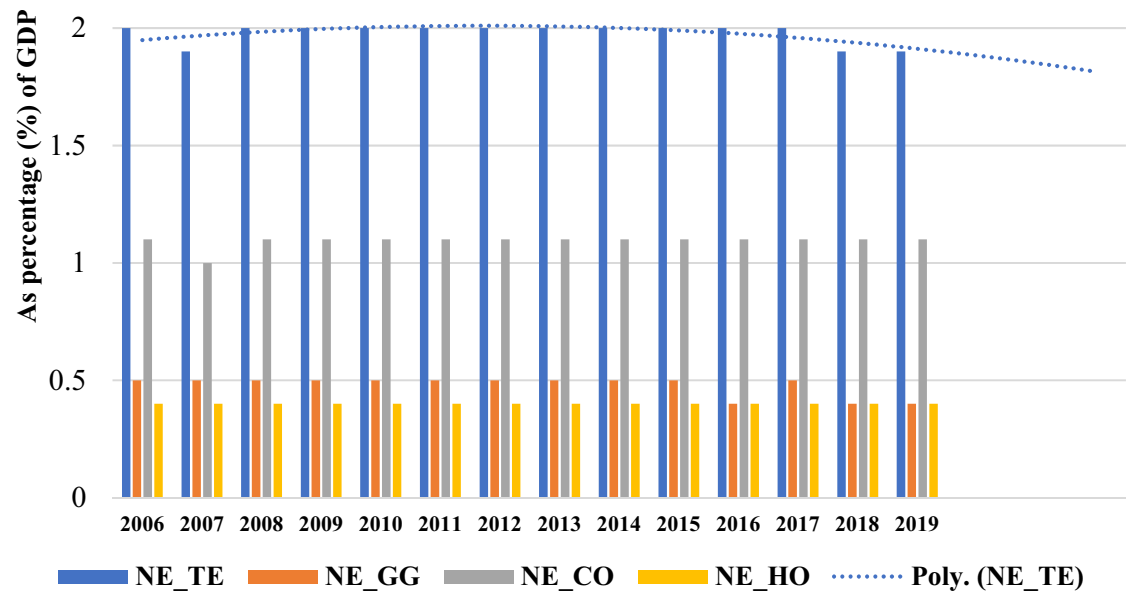

Notes: 1) NE_TE = National expenditure on environmental protection (NEEP): Total economy. NE_GG = NEEP: General government and non-profit institutions serving households. NE $\mathrm{CO}=$ NEEP: Corporations. NE HO = NEEP: Households.

2) Data for EU-27 are estimated by Eurostat.

Fig. 1 The evolution of national expenditure on environmental protection (NEEP) of total economy and its composition by institutional sector throughout the EU-27 as percentage of GDP during the period 2006-2019. Source: Eurostat (last update: 30/07/2020)

is possible that environment is close to no longer being a luxury good, which used to be the common conviction a few decades ago. ${ }^{25}$ Finally, it is useful to pinpoint the case of year 2009, which is the first year after the global economic crisis of 2007-2008. During that year, GDP dropped by $4.49 \%$ whereas the environmental expenditure only went down by $0.32 \%$. An explanation might be that sustainability was proposed as a measure to counteract the recession. Could we expect a similar response to the ongoing crisis?

\section{The effects of the COVID-19 pandemic on the European Union sustainable development}

Since December 2019, the global community is being affected by a pandemic of the severe and highly contagious respiratory syndrome COVID-19 caused by a novel coronavirus (SARS-CoV-2) (WHO 2020), to which governments worldwide have responded with restrictions on social contact and reduced mobility and economic activity and even partial and total lockdowns. As a result, the pandemic has fueled

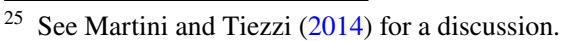




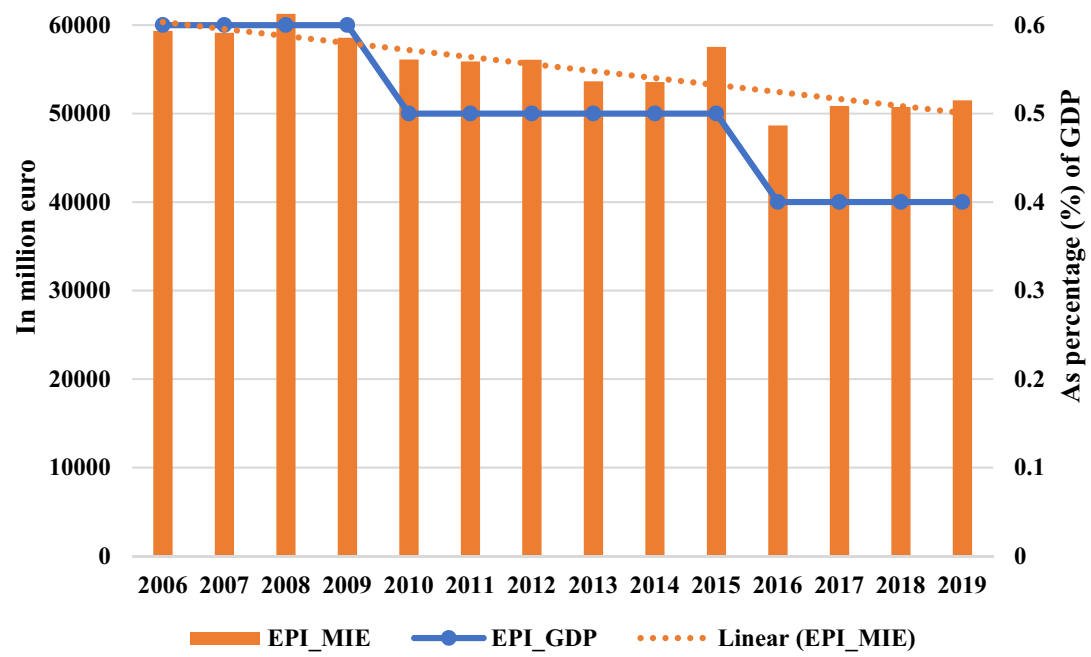

Notes: 1) EPI_MIE = Investments for environmental protection in total economy in millions of euros. EPI_GDP $=$ Investments for environmental protection in total economy as percentage of GDP.

2) Data for EU-27 are estimated by Eurostat.

Fig. 2 The evolution of investments for environmental protection throughout the EU-27 in million euro and as percentage of GDP during the period 2006-2019. Source: Eurostat (last update 15/09/2020)

a multidimensional crisis, namely a medical, a social and an economic which has reshaped both the formulation and the exercise of economic policy ${ }^{26}$ in general and the goals of sustainable development in particular, both at the national and at the European level. In this part of our paper, we attempt to make some preliminary assessments as to how the coronavirus crisis is expected to affect the conduct of general economic policy, both at the EU central level and at the level of the individual member states. Then, a broad assessment of the impact of the COVID-19 pandemic on the individual 17 SDGs of the European sustainable development strategy is attempted.

The coronavirus pandemic, both globally and at EU level, served as a crucial opportunity to reassess and reposition the economic and social role of the state that had prevailed in recent decades. In the pre-COVID period, the prevailing view of the economic role of the state was the neoclassical approach that focuses on minimising state intervention in the economy and recognises the dominant role of the market. In other words, the coronavirus pandemic created a tendency to restore the interventionist economic role of the state, especially its protective function, by shifting back

\footnotetext{
${ }^{26}$ For an analysis of the economic issues raised by the coronavirus pandemic, see mainly Baldwin and Weber di Mauro (2020), while for an overview of the economic, social and political issues raised by the pandemic, see Tisdell (2020).
} 


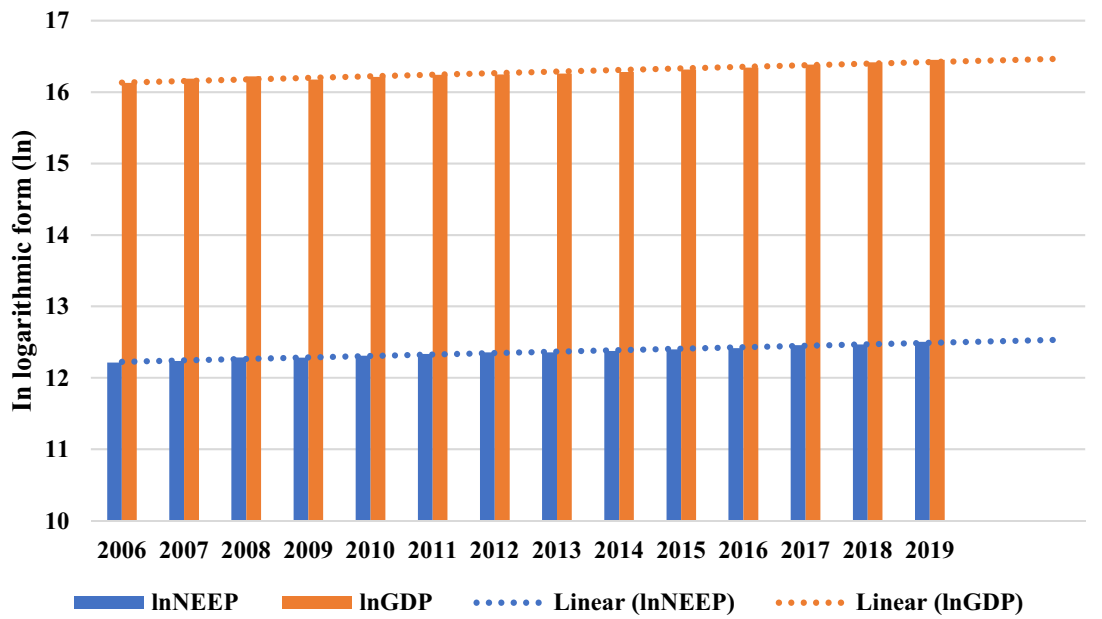

Notes: 1) NEEP = National expenditure on environmental protection throughout the EU-27. GDP = Gross Domestic product at market prices throughout the EU-27.

2) Data are in logarithmic form (ln). Initial data in millions of euros.

3) Data for EU-27 are estimated by Eurostat.

Fig. 3 The evolution of national expenditure on environmental protection and of GDP throughout the EU-27 during the period 2006-2019 in logarithmic form(ln): Initial data in millions of euros. Source: Eurostat (last update: 10/11/2020).

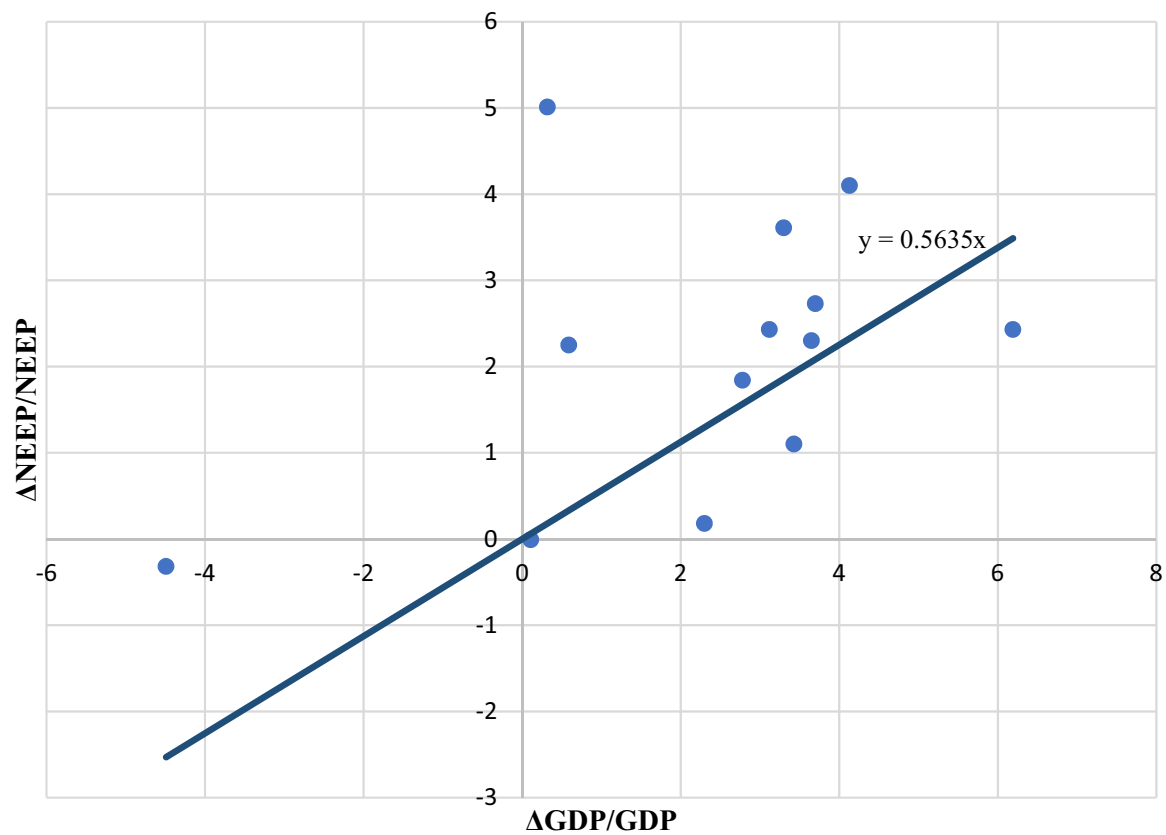

Fig. 4 The relationship between national environmental expenditure growth and GDP growth in the EU-27 during the period 2007-2019. Source: Fig. 3 
the balance from the market to the state (Bergsen 2020) or at least by bolstering public authority over private agency (DeWit et al. 2020).

This is very likely a temporary reaction, given the prevailing political forces in Europe, although it could pave the way for a more permanent re-establishment of the enhanced economic role of the state as a guarantor of the functioning of the economy. ${ }^{27}$ In any case, due to the pandemic, the cruciality of the social dimension of sustainability has unavoidably been brought into the light. Political and economic inequalities have long been correlated with environmental degradation ${ }^{28}$ and bad health and mortality ${ }^{29}$ but the pandemic made the importance of social goals like health insurance, access to healthcare, clean water and sanitation, quality education and gender equality impossible to ignore. ${ }^{30}$ At the same time, the associated SDGs are under the most severe threat as a result of the pandemic (Naidoo and Fisher 2020). Regarding the environmental criterion of sustainable development, the impact of COVID is more complicated. It appears that the pandemic has contributed, at least for now, towards goals associated with air pollution, greenhouse emissions, land and wildlife pressure but it has led to an increase of single-use plastics and shifted priority on waste management (Silva et al. 2020). Summing up, the shortcomings of leaning back to traditional economic growth have been made obvious and, given the certainty of future stressors that will come up as a result of climate change, SDGs will need to be more determinately pursued and become more resilient.

At the EU level, the economic implications of COVID-19 vary from country to country, but all governments, regardless of their ideological spectrum, have made and continue to make major interventions to the economy. Historically, these interventions are of an unprecedented scale. For example, the pandemic has led to the activation for the first time of the General Escape Clause (GEC), temporarily freezing the fiscal adjustment process. The GEC allows member states to take budgetary measures bypassing the Stability and Growth Pact (SGP) conditions of fiscal consolidation to deal with the economic and social consequences of the coronavirus pandemic. $^{31}$

Moreover, at the EU level the Recovery and Resilience Facility or, as it is often called, the Recovery and Resilience Fund (RRF) has been established to support the countries and economic sectors that have suffered the most, by providing loans and grants for the first years of the recovery. RRF is the key recovery instrument at the

\footnotetext{
27 At the EU level, the shift in the state-market balance, if made long-term, could jeopardize or at least alter the path to European integration, which to date has been based on the strategic position of limiting the state's ability to intervene in the market process (Bergsen et al. 2020).

28 See for example Boyce (2007) and Drabo (2011).

29 See for example Lynch et al. (2000)

30 See for example Naidoo and Fisher (2020) and Ottersen and Engebretsen (2020).

31 The GEC was first established in 2011 but it was activated in 2020. According to the GEC, in times of severe economic downturn in the euro area or in the Union as a whole, member states are allowed to temporarily deviate from the adjustment path to meet the medium-term budgetary objective. See, Communication from the Commission to the Council on the activation of the general escape clause of the Stability and Growth Pact, Brussels, 20.3.2020, COM(2020) 123 final.
} 
heart of the more general "Next Generation EU Recovery Plan" (Next Generation EU) that aims to address the damage caused by the coronavirus pandemic. ${ }^{32}$ The Next Generation EU is expected to help the EU to emerge stronger and more resilient from the pandemic (European Commission 2020b).

The basic aim of the RRF is to mitigate the economic and social impacts of the COVID-19 pandemic in the crucial first years of recovery. In this context, European member states must prepare their national recovery and resilience plans (NRRPs). These plans have to set out coherent packages of reforms and public investment projects that must be implemented by 2026. NRRPs are expected to contribute to four general aims specified in the 2021 Annual Sustainable Growth Strategy. ${ }^{33}$ The first aim, namely the "Green Transition", is of particular importance as far as the NEEP is concerned, since NRRPs must focus on reforms and investments supporting the so called "green transition". It is therefore expected that the NEEP will increase significantly due to the funds that will be allocated by the RRF. Especially, we expect that public and private investment in environmental protection is going to increase, mainly in the sectors of clean technologies and renewables.

We must note at this point that, although the RRF was set up solely to mitigate the economic and social impacts of the coronavirus pandemic, we hope that it can be the basis for EU policy-making in the future in the case of balanced economic disturbances, that is disturbances affecting all countries or at least a large number of countries, given that, according to the Treaty of the European Union, these are the only disturbances in the face of which monetary policy can be used.

As for the implications of COVID on the SDGs, even before its outbreak it was clear that the objectives of the "2030 Agenda" would not be met, neither globally not at the EU level. Most of the 17 SDGs were already lagging behind their target levels and the pandemic has worsened the existing difficult global condition, as it is estimated that it has negatively affected most of the SDGs and their respective targets. ${ }^{34}$ According to the UN, the coronavirus pandemic has exercised first and second order negative effects on 13 SDGs, namely SDGs 1-8, 10-11, 13 and 16-17 (UN 2020). A large number of studies has already been published trying to assess the impact on the SDGs. However, these studies are associated with a significant weakness since they try to capture only the initial impact of COVID-19 on certain SDGs (United Nations, Sustainable Development Goals Report 2020). That is, they focus on the short-term effects of the pandemic. The existing research on the long-term effects of the pandemic is rather speculative and opinionated (Nerini et al. 2020). Assessing

\footnotetext{
32 We must note that the RRF mechanism was introduced at the insistence of the so-called "frugal four" fiscally conservative European countries, namely Austria, Denmark, the Netherlands and Sweden (Sapir 2020).

33 European Commission, Communication from the Commission to the European Parliament, the European Council, the Council, the European Central bank, the European Economic and Social Committee, the Committee of the Regions and the European Investment Bank, "Annual Sustainable Growth Strategy 2021”, Brussels, 17.9.2020, COM (2020) 575 final.

34 Nerini et al. (2020) estimate that the pandemic has affected negatively all the 17 SDGs and $90 \%$ of the targets associated with them, while Barbier and Burgess (2020) estimate that the coronavirus has exerted a negative impact on 12 of the 17 SDGs. Mukarram (2020) argues that the pandemic is going to affect either explicitly (directly) or implicitly (indirectly) all the SDGs.
} 
the economic impact of the pandemic, especially the longer-term one, becomes even more difficult due to the high degree of uncertainty associated with the evaluation of its effects on key macroeconomic variables, such as output, investment, consumption and employment and the lack of close historic parallels. ${ }^{35}$

Similar concerns emerge with regard to the impact of the pandemic on the 17 SDGs. To date, to our knowledge, no study has been published that investigates systematically the exact quantitative effects of the coronavirus pandemic on each of the 17 SDGs. In the EU case, the most recent monitoring report, that is the 2020 report, as it has already been stated, does not include any quantitative estimates of the implications of the COVID-19 pandemic on SDGs. However, it acknowledges that the pandemic is likely to have negative implications for the EU's overall progress towards the SDGs (Eurostat 2020a).

The most important channel through which the coronavirus pandemic affects the SDGs is through the reduction of GDP caused by the efforts to deal with the pandemic, mainly by shutting down the non-essential economic activities. However, the COVID-19 pandemic does not affect all European economies in a balanced way with its differentiated effects being attributed to a number of factors, such as the structure of the economy and in particular the share of tourism in GDP, the quality of governance, the ability of the government to pursue expansionary fiscal policies or the fiscal capacity of government, the severity or strictness of the lockdown measures implemented, the level of social development and the extent of the informal or shadow economic activity. ${ }^{36}$ Generally, governments have been faced with a difficult trade-off problem as Tisdell formulates it. That is, how much reduction in economic activity and employment must be accepted as a result of allowing more liberal social interaction (Tisdell 2020). Or, as Susskind and Vines have put it, a trade-off between reducing the number of lives lost and rising economic costs (Susskind and Vines 2020). In this dilemma, that has in its core the value of life, there are large discrepancies in the attitude of governments and the severity of restrictions.

Regarding the forecasts of the evolution of GDP, according to the most recent Eurostat estimates, at the time this paper was prepared/written, the average EU-27 GDP growth rate in 2020 is expected to fall by $6.1 \%$, while in 2021 and 2022, the average EU-27 growth rates are expected to be $4.2 \%$ and $4.4 \%$, respectively (European Commission 2021). Moreover, the general government budget balances have suffered significant deficits. The average EU-27 budget balance for 2020 is estimated to have a deficit of $6.9 \%$ of GDP. This is expected to rise to $7.5 \%$ of GDP in 2021 and to fall to $3.7 \%$ of GDP in 2022 (European Commission 2021). ${ }^{37}$

Given that the elasticity of environmental expenditure is, on average, close to 1, we expect that, at the EU level, it will be reduced at a similar rate. However, it

\footnotetext{
35 For an analysis of the economic uncertainty associated with the COVID-19 pandemic, see Altig et al. (2020).

36 For an empirical analysis of the effects of some of these factors, see Sapir (2020).

37 The previous estimates were that the average EU-27 growth rate in 2020 was expected to fall by $6.4 \%$ in 2020 (Eurostat 2021), while in 2021 and 2022 the average EU-27 growth rates were expected to be $5.1 \%$ and $4.5 \%$ respectively (Eurostat 2020 a).
} 
is possible that the decrease in environmental expenditure will be smaller if, as in 2009, sustainability emerges as a way out of the crisis.

Finally, there are those countries that have been hit hardest in 2020 by the coronavirus pandemic. These countries are Spain (with an estimated GDP decline of $10.8 \%$ ), Italy (GDP fall by $8.9 \%$ ), Greece (GDP fall by $8.2 \%$ ), ${ }^{38}$ France (GDP fall by $8.1 \%$ ), Croatia (GDP fall by $8.0 \%$ ), and Portugal (GDP fall by $7.6 \%$ ) (European Commission 2021). At the same time, some other European countries are estimated to have been less affected by the pandemic. These are Lithuania (GDP fall by $0.9 \%$ ), Luxembourg (GDP fall by 1.3\%), Denmark (GDP fall by 2.7\%), Poland (GDP fall by $2.7 \%$ ), Sweden (GDP fall by $2.8 \%$ ) and Finland (GDP fall by $2.8 \%$ ) (European Commission 2021). It seems that the countries most affected by the coronavirus pandemic are those more dependent on tourism. And, even if some economies are expected to see their GDP bounce back to its pre-pandemic levels by the end of 2021 or early 2022, the forecast for the aforementioned nations is that it will most likely take a lot longer (European Commission 2021). Greece, for example, is estimated to recover from the pandemic losses and return to its pre-pandemic level of GDP in 2022 (Eurostat 2020a; European Commission 2021). ${ }^{39}$

\section{Conclusions}

From the investigation of the evolution over time of the actually pursued sustainable development strategy, we find that both at the level of the EU and the UN, whose policy is closely followed by the EU, its content is gradually reduced. The social component of sustainability seems to have been largely abandoned. And the sustainable development strategy in its current form has essentially been limited to that of green growth strategy, with an emphasis on economic growth. In other words, there is a gradual restoration of the core of the traditional economic growth policy. At the EU level, this tendency emerges from both the analysis of the content of its green growth strategy as well as from the examination of the evolution of the index of national environmental expenditure as well as from the environmental protection investment index during the period 2006-2019. We argue that the main impact of the coronavirus pandemic has been to reveal just how fragile this growth plan is. As Naidoo and Fisher put it, "growth cannot continue forever on a planet that is already over-exploited" (Naidoo and Fisher 2020). In terms of the specific SDGs that have been set at the EU level, although there is continuous readjustment of the required data, the estimates of GDP losses and the length of the recovery period, all estimates converge in favour of the view that the pandemic will have negative implications on almost all SDGs, at least in the short term. The long-term effects of the pandemic cannot even be outlined, especially at the level of each individual EU member state,

\footnotetext{
${ }^{38}$ For an analysis of the estimated effects of the COVID pandemic on the Greek economy (GDP, employment and trade balance), see Mariolis et al. (2021).

39 Given that the cumulative GDP growth rate of 2021 and 2022 is estimated that it will offset the losses of 2020. See, European Commission (2021), pp. 68-69 and Statistical Annex, Table 1, p. 149.
} 
as they depend on a number of factors, often country- specific. Nevertheless, the effectiveness of RRF, as the key instrument of recovery at the European level, established for this purpose, will play a decisive role in minimising or even neutralising the negative longer-run effects of the coronavirus pandemic.

\section{Declarations}

Conflict of interest On behalf of all authors, the corresponding author states that there is no conflict of interest.

\section{References}

Altig D, Baker S, Barrero JM, Bloom N, Bunn Ph, Chen S, Davis SJ, Leather J, Meyer B, Mihaylov E, Mizen P, Parker N, Renault T, Smietanka P, Gr T (2020) Economic uncertainty before and during the COVID-19 pandemic. J Pub Econ 191:104274

Baldwin R, Weber di Mauro B (2020) Economics in the time of COVID-19. CEPR Press

Barbier EB, Burgess JC (2020) Sustainability and development after COVID-19. World Dev 135:1-15

Bergsen P (2020) A new political economy for Europe post-COVID-19, wilfried martens centre for European Studies. Eur View 19(2):131-137

Bergsen P, Billon-Galland A, Kundnani H, Ntousas V, Raines T (2020) Europe after coronavirus: the EU and the new political economy. Chatham House

Boyce JK (2007) Is inequality bad for the environment? in equity and the environment. Emerald Group Publishing Limited

DeWit A, Shaw R, Djalante R (2020) "An integrated approach to sustainable development, national resilience, and COVID-19 responses: the case of Japan. Internat J Disaster Risk Reduct 51:1-6

Dietz S, Adger NW (2003) Economic growth, biodiversity loss and conservation effort. J Environ Manage 68:23-35

Dinda S (2004) Environmental Kuznets curve hypothesis: a survey. Ecol Econ 49:431-455

Drabo A (2011) Impact of income inequality on health: does environment quality matter? Environ Plan 43(1):146-165

European Commission (2020a) Directorate E: Sectoral and Regional Statistics, Environmental Indicator Catalogue (as for 26 November 2020): Indicator name (producer_indicator code).

European Commission (2020b) Next Generation EU: commission presents next steps for the €672.5 billion recovery and resilience facility in 2021 annual sustainable growth strategy, Press release, Brussels.

European Commission (2021) Directorate-general for economic and financial affairs, European economic forecast: spring 2021, European economy, institutional paper 149, Luxembourg.

Eurostat (2020a) Sustainable development in the European union: monitoring report on the progress towards the SDGs in an EU Context: 2020 Edition (4rth edition). Luxembourg.

Eurostat (2020b) Environmental protection expenditure accounts: statistics explained.

Eurostat (2020c) Environmental protection expenditure accounts: key environmental protection and economic indicators EU-27, 2006-2019.

Eurostat (2021) Newsrelease euroindicators, 17/2021.

Fetting C (2020) The European green deal ESDN Report. ESDN Office

Foster JE (1998) What is poverty and who are the poor? Redefinition for the United States in the 1990's: absolute versus relative poverty. Am Econ Rev Papers Proc Hundred Tenth Ann Meet Am Econ Assoc 88(2):335-341

Lynch JW, Smith GD, Kaplan GA, House JS (2000) Income inequality and mortality: importance to health of individual income, psychosocial environment, or material conditions. BMJ 320(7243):1200-1204. https://doi.org/10.1136/bmj.320.7243.1200

Mariolis TH, Rodousakis N, Soklis G (2021). Inter-sectoral analysis of the Greek economy and the COVID-19 multiplier effects. European Politics and Society (forthcoming). 
Martini C, Tiezzi S (2014) Is the environment a luxury? An empirical investigation using revealed preferences and household production. Resour Energy Econ 37:147-167

Mori A, Ueta K (2007) Beyond green growth: sustainable development in East Asia. Kyoto University

Mukarram M (2020) Impact of COVID-19 on the UN sustainable development goals (SDGs). Strateg Anal 44(3):253-258

Naidoo R, Fisher B (2020) Sustainable development goals: pandemic reset. Nature 583:198-201. https:// doi.org/10.1038/d41586-020-01999-X

Nerini FF, Henrysson M, Swain A, Swain RB (2020) Sustainable development in the wake of COVID-19. Research Square, pp 1-15

O'Connor D (1996) Grow now/clean later, or pursuit of sustainable development? OECD technical paper no 111. OECD

OECD (2009a) Declaration on green growth, (C/MIN(2009)5/ADDI/FINAL).

OECD (2009b) OECD and green growth. OECD

Ottersen OP, Engebretsen E (2020) COVID-19 puts the sustainable development goals center stage. Nat Med 26:1672-1673. https://doi.org/10.1038/s41591-020-1094-y

Pearce D, Palmer C (2001) Public and private spending for environmental protection: cross-country policy analysis. Fisc Stud 22(4):403-456

Pearce D, Barbier E, Markandya A (1990) Sustainable development: economics and environment in the third world. Edward Elgar

Pegels A, Altenburg T (2020) Latecomer development in a "greening" world: introduction to the special issue. World Dev 135:105084

Purvis M, Grainger A (2004) Exploring sustainable development: geographical perspectives. Earthcan

Sapir A (2020) Why has COVID-19 hit different European Union economies so differently? Policy Contribution No. 18. pp. 1-13.

Silva ALP, Prata JC, Walker TR, Duarte AC, Ouyang W, Barcelò D, Rocha-Santos T (2020) Increased plastic pollution due to COVID-19 pandemic: Challenges and recommendations. Chem Eng J. 126683.

Susskind D, Vines D (2020) The economics of the COVID-19 pandemic: an assessment. Oxf Rev Econ Policy 36(S1):S1-S13

Sustainable Development Solutions Network (SDSN) and Institute for European Environmental Policy (IEEP) (2020) The Europe sustainable development report: meeting the sustainable development goals in the face of the COVID-19 pandemic, Paris and Brussels.

Tisdell CA (2020) Economic, social and political issues raised by the COVID-19 pandemic. Econ Analy Policy 68:17-28

UN Economic and Social Commission for Asia and the Pacific (UNSCAP) (2005), Annotated Provisional Agenda, E/ESCAP/SO/MSCED(05)/L.2.

United Nations (UN) (2001) Department of economic and social affairs, division of sustainable development, indicators of sustainable development: guidelines and methodologies, New York.

United Nations (UN) (2002). Department of economic and social affairs, global challenge, global opportunity: trends in sustainable development: guidelines and methodologies, New York.

United Nations (UN) (2015) Transforming our world: The 2030 agenda for sustainable development, A/ RES/70/1, New York.

United Nations (UN) (2020). Shared responsibility, global solidarity: responding to the socioeconomic impacts of COVID-19.

Vavouras I (2011) From sustainable development to green growth: the abandonment of the social character of development. Soc Cohesion Dev 6(1):27-35

World Commission on Environment and Development (1987) Our common future. Oxford University Press

World Health Organization (WHO) (2020). Director-General's opening remarks at the media briefing on COVID-19-11 March. 2020 https://www.who.int/dg/speeches/detail/who-director-general-s-openi ng-remarks-at-the-media-briefing- on-covid-19. (Accessed 11 Mar 2020).

Publisher's Note Springer Nature remains neutral with regard to jurisdictional claims in published maps and institutional affiliations. 